\title{
The Shift to Online Assessment Due to COVID-19: An Empirical Study of University Students, Behaviour and Performance, in the Region of UAE
}

\author{
Liaqat Ali and Nidal Abidal Hamid Hmoud Al Dmour
}

\begin{abstract}
The education system has dramatically changed from physical to online due to COVID-19. Millions of learners around the world have been affected due to the pandemic caused by coronavirus. The emergence of COVID-19 has forced educational institutions to divert all strategies from physical to online platforms for the safety of the students, instructors, and all the other staff members. The processes of examining students and their assessment strategies are heavily affected due to the sudden adoption of online education than physical education at campus. The research in this paper discusses issues relevant to online assessments and the strategies used by the universities due to COVID-19 in the region of UAE. The research collected data through an online questionnaire from 312 undergraduate university students in UAE to understand their behaviour. Furthermore, their performance of online assessment is gauged through the analysis of exams transcripts and comparison is made with their previous GPA and CGPA to understand the effects of COVID-19 on their overall performance. Semi-structured interviews were conducted to discuss issues related to e-assessment and recommendations are made to improve the online assessment process in universities. The research proves that students have benefited from the online assessment.
\end{abstract}

Index Terms-Covid-19, Corona, e-assessment, university, students, online education.

\section{INTRODUCTION}

Covid-19 is a worldwide pandemic caused by the SARS-Cov-2, a newly discovered coronavirus which causes respiratory illness. First noticed in Wuhan, China, the coronavirus has impacted the world physically as well as financially, bringing down businesses and hitting the economy. As of June 2020, there have been a total of 9.1 million cases resulting in the deaths of more than 470,000. As the virus has impacted 216 countries, many facilities such as schools, leisure centres, barbers and more, have had to temporarily shut down [1].

Due to the pandemic's risk of spreading further, many countries have shut down their educational facilities. Over a billion learners have been affected and there are 116 country-wide closures [2]. As a result, the education of students has been halted and many have been forced to take

Manuscript received July 27, 2020; revised January 24, 2021.

Liaqat Ali is with the Department of Information Technology, College of Engineering and Information Technology, University of Science and Technology of Fujairah, P.O. Box: 2202, Fujairah, United Arab Emirates (e-mail: liaqat22@gmail.com).

Nidal Al Dmour is with the Department of Information Technology, College of Engineering and Information Technology, Ajman University UAE (e-mail: nidal75@yahoo.com). classes online. This has popularized online educational tools such as Zoom to be used by educational facilities across the globe. The increased popularity of online education has resulted in debates on whether it is more efficient to use online tools or physical tools to educate learners.

There are many advantages to online education compared to physical education. For example, online education allows more flexibility with time. This is because students do not have to travel to the university campus and therefore there is less risk of tardiness. Students that are employed are thus able to manage their work-life and student life more efficiently. Another advantage is that online learning is more cost-effective. Students and teachers do not have to pay for transport to the university campus and teachers can be supplied with pre-made slides to give to the students. Online education also allows there to be a virtual classroom instead of a physical one. This allows the maintenance cost of classrooms to decrease.

However online learning also has its drawbacks. Online learning deeply relies on various online tools and $\mathrm{Wi}-\mathrm{Fi}$ connectivity. If servers are down or Wi-Fi connections are weak, online classes can be inaccessible and therefore not as reliable. The server may not be able to support the number of students in the class and therefore crash. There are also many risks to cybersecurity when it comes to online education. The threat of an online classroom being hacked is possible unlike in physical classes [3], [4].

Assessments also must be conducted online due to the closure of educational facilities. There are many drawbacks to this as the chances of students cheating increases. For example, online assessments are done by students on their own devices at home therefore they cannot be checked upon and so they are more likely to cheat. Internet usage is considered a catalyst for e-assessment cheating [5]. As a result, questions must be prepared so that they cannot be acquired easily from textbooks. This can make the process of creating exams more difficult and add strain to the staff and teachers. Creating exams needs a new perspective unlike assessments taking place in physical classrooms, where the risk of students cheating is lower compared to that during online assessments as there is an invigilator present in the room with them. Universities believe that if student webcams are on, they can detect any cheating, however, this is not the case as there are many sly methods students can use to cheat. Students can use a variety of tools to cheat during online assessments, like the use of multiple windows on their computer screen or the use of their phones. Students can also take glances at their notes without the teacher noticing. 
Another disadvantage of online tests is that due to the limit of students in each online classroom the same exam may have to be taken separately. This allows there to be communication between the students about questions and answers. As students are more likely to cheat during online assessments, as they are easily able to, students that do not resort to cheating may be demotivated due to their scores compared to others. This can cause moral students to cheat, thus adding to the inaccurate scores on exams.

Even though online assessments offer ease and are more cost-efficient than physical assessments, there are still many infrastructural barriers. A stable internet connection, electric connection, and other infrastructural issues must be considered when universities consider the audience of the online exam. If the connection ceases mid-exam, not only do students have an opportunity to teach but also jeopardise their concentration, leading to lower inaccurate results.

Online examinations also restrict collaborative projects and specific examinations. Due to its current limits and framework, the tools used for online assessments are objective, focusing on mostly written examinations. Online assessment tools do not allow examinations of students studying arts or any group projects, where students are handed a group task and judged on their result. This restricts a full evaluation of students across the university courses and shows that online assessments only allow specific examinations [6]-[8].

\section{LITERATURE REVIEW}

In higher education specifically, the development of technologies has been improving the assessment system [9]. Technology is central to learning and therefore as a result has proved itself to be central to assessment [10]. Technology has therefore drastically shaped the education field [11]. To conduct online assessments and create online classes, various tools are being used by educational facilities. Applications such as Zoom, WebEx, Microsoft Team, and Skype are being used to allow students to attend online classes. These video telephony and online chat services connect students and teachers via the internet.

Tools used for conducting online assessments have also begun to popularize. Tools such as Blackboard Learn, and Lockdown Browser are being used to allow students to perform examinations at home. These tools allow for more fair and valid tests as they perform certain actions that take measures to prevent students from using third party software during assessments to cheat. Online assessment tools are made with the purpose of cutting down as much cheating as possible, however they are not perfect and can be bypassed. With the rise of online formative assessment during the COVID-19 pandemic, online assessment tool usage has been on the rise and therefore more companies are taking the opportunity to advertise their online assessment software. A wider use of e-assessment would require a more thoughtful understanding on how innovative technologies and tools can be effectively integrated into the assessments [12].

Assessments are a crucial aspect of the teaching and learning process in higher education institutions [13]. This is because, not only do assessments indicate the progress of the student to the teacher and the university, but also put the students through a mock scenario of how their final assessment will be, giving them better preparation and an indication of future exams. Due to advancements in technology and online learning tools and systems, an online assessment format has become a viable means of assessing students in such systems [13]. However, this always brings up the question as to whether or not the validity of online assessments is comparable to that of traditional methodologies due to the fact that students have immediate access to a wide range of forbidden tools which they can use to their advantage and therefore there are many critiques of current e-assessment policies [14]. Compared to in house assessment methods, online assessment encompasses different characteristics [15]. Although e-assessment has advantageous properties compared to standard assessment methods, such as saving time for the teachers to correct the paper [16]. E-assessment however does provide advantages such as reducing the tutors time and effort and therefore being introduced into the education system [17]. There are multiple qualitative methodologies that can be used to conduct online assessments. For example, task-based simulations can be used. This is a form of adaptive e-assessment where students must use given resources and skills to complete a task in a safe virtual environment [18]. The task simulation must be as realistic as possible in order to assess their performance in context. Another methodology that can be used is giving students open ended questions. These are questions with no right or wrong answers, rather they allow online students to reflect on the topic and draw in their own conclusions. Problem solving case studies can be another form of assessment that can be used for online testing. This encourages learners to solve a problem whilst also displaying their current knowledge. The ability to solve problem can be seen through the observations the students make [19] .This case study can be either a real world example or a theoretical scenario where the students will have only their own knowledge to rely on as they work to solve the problem at hand. Education institutions can also use online group collaboration projects to gather assessment results. Learners can work together to solve a problem and also assess the performance of their peers with peer-feedback. However, the effectiveness of these formative e-assessments depends on student attitudes towards the different aspects of online formative assessments [20].

Like all endeavours towards education, there are still many flaws in online education and assessments. Assessment is a very sensitive activity where the teacher must take extra care when formatting it [21]. From its fairness to robustness, online learning has only scratched the surface. Without a doubt, as technology advances, the popularity of online learning will increase and as a result, present tools being used will need to be updated to battle with the current disadvantages of online education.

There are many improvements required for the infrastructure of online education. As of now, a strong Wi-Fi connection and a capable computer system are needed to allow students who attend online classes to receive a stable connection. Some e-learning platforms use cloud services that are straining on the internet connection and can have 
cybersecurity threats. E-learning platforms should seek to improve protection and allow students with weaker infrastructure to be able to access their services with ease.

Online assessments also allow fraudulent examinations, in which students are capable to cheat. This provides inaccurate results and thus causes unfairness within the grading system. E-learning services should look to provide assessments tool which conducts exams in fairness with accuracy. They should reduce the capability of cheating and fraud within online examinations by either performing unorthodox methodologies of assessments or thoroughly using online assessment tools which aim to prevent cheating to the highest degree possible. These methodologies should come with pre planned learning materials for highest possible efficiency [22].

An online formative assessment method has been the primary method of assessment for all educational institutions across the globe [23]. Due to the closure of all campuses and no more face to face teaching, students are now also taking their exams and assessments mostly online as well. E-assessments are currently a major concern to all educational institutions worldwide [24]. Before the pandemic ensued, in-house, traditional methods of assessment were the only form of acceptable assessments that would give valid results. This is solely due to the nature of online assessments as it can be very easy for students to cheat whilst participating This is because students have immediate access to the web and a variety of other tools that give then a distinct advantage that they would not have in traditional assessment methods. Also, the fact that it is basically impossible to invigilate student behaviour during online assessments means that students are more than likely to rely on cheating methods as they have no means of being caught by exam invigilators. However, due to the fact that in-house assessments are not possible, e-assessments are the only format that educators can rely on in order to view student performance and progression. Online assessments are now the main way to assess students across all educational institutions due to the fact that students can perform them safely from a virtual classroom. Due to the disadvantages that come with e-assessments, educators should pre-determine the purpose of the assessment and the criteria that is to be measured [25].

It is important that educators consistently keep an eye on the progression and dedication of the students during times when they are away from the classroom. Assessment is the core of higher education [26]. Formative e-assessment is not only an integral part of teaching but also a good learning experience [27]. Online examinations are being increasingly implemented in higher education institutions [28]. Universities have adopted e-assessments due to obtain a more accurate and faster method to assess students, rather than traditional paper-based assessments [29]. Although it can be bypassed in some ways, online assessments are the best way to give educators an insight on whether or not students are progressing. Online assessments therefore become a near integral part of the process to determine whether or not the aims and objectives of education are being met. E-assessments are beneficial as they improve student learning. Assessment is important because it has a strong impact on student learning [30]. Testing students and telling them before-hand motivates the student to study and learn more as they wish to perform to the best of their abilities in the upcoming assessment. Later on, the educator is able to analyse the performance of the students and evaluate which topic subject the students had the most difficulty in and which needs to be focused on the most. Teachers can evaluate student competencies and knowledge through e-assessment [31]. This analysis of the assessment performance allows the educators to identify the challenges of the course and assignment. This intern also improves instruction by identifying what types of instructional adjustments need to be made in order to fit the course better. Although creating an engaging and effective assessment strategy is considered one of the most difficult areas in learning design [32] , carrying out this process makes it so that student grading is more reflective of the students learning towards the course outcomes and the students skills and therefore making the grading of the students more systematic and objective.

\section{RESEARCH METHODOLOGY}

In the first phase, the primary data of this research is collected through the online close-ended questionnaire from 312 undergraduate students of different programs from the universities of UAE. The online questionnaire was developed through 30 different questions covering aspects of online assessments including the gender of the survey respondents. Majority of the students were from University of Science and Technology of Fujairah and Ajman university of UAE. However, students from UAE University also participated in the survey of this research. In addition, other organization such as Ministry of Education and Ministry of Health also participated in the survey of this research. The answers collected from 312 survey respondents are gauged on the scale of Strongly Agree, Agree, Neutral, Disagree, and Strongly Disagree. The responses were collected during the period of Saturday 20 June 2020 - Friday 26 June 2020.

In the second phase of the research, semi-structured interviews with 30 different students were conducted to understand their behaviour and preference for the online assessment and education. Students showed a very high interest and presented their views, comments, and suggestions for either online or physical assessments on the campus.

In the third phase of the research, the authors of this research analyzed 61 student's transcripts across two universities, university of science and technology of Fujairah and Ajman university UAE, from different programs and data is analyzed from 2016-2020 to understand their performance and its effects due to online assessment.

\section{FINDINGS AND DATA ANALYSIS}

The research in this paper collected primary data through online questionnaire where 312 undergraduate students participated in the survey. The online questionnaire was made by 30 close ended questions where the first question was about their gender only. The further sections of this paper elaborate the data findings and analysis of these 
findings.

\section{A. Online Survey Respondents and Their Gender}

The survey of this research found that both male and female students revealed their high interest and participated in the survey.

As shown in the figure below, $76.3 \%$ of participants in this survey were female, while $20.5 \%$ were male. However, $3.2 \%$ students preferred not to mention their gender. This concludes that the majority of participants who conducted the survey were female.

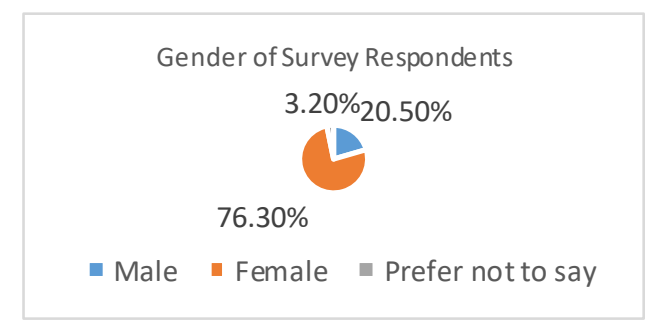

Fig. 1. Gender of online survey respondents.

\section{B. Data Analysis and Findings}

Table I, containing 29 close ended questions covering major aspects of online assessments to understand student's behaviour below shows the data collected through the survey of this research.

\section{Survey Questionnaire}

Following were the questions asked in the survey of this research.

1) I have a good prior experience of online assessments/examinations?

2) It is easier to take an online assessment than physical assessment in the university.

3) I have browsed among web pages easily during online assessment.

4) I have followed the direction of online assessment without any problem.

5) I believe online assessment is more transparent and fairer than physical assessment on campus.

6) Cheating is more difficult in online assessment than physical assessment.

7) The use of other applications such as WhatsApp is possible during online assessments and students can benefit from such applications

8) Physical examinations on campus provide a better environment than online assessments as teachers could be contacted if there is any clarification required about a particular question.

9) I believe my computer literacy and typing skills is a barrier in online assessment.

10)Online assessment contains more questions than physical assessment and it is important that students must have deep study of the subject to be successful.

11) Time management is more difficult in online assessment than physical assessment on campus.

12)Online assessment is consistent with the teaching styles.

13)Online assessments are more efficient and effective than physical exams on campus.
14)Online assessments are more systematic than physical exams on campus.

15)I am happy with the user interface/tool used for online assessment by my university.

16)I believe online assessment offers more opportunities than paper alone based assessment.

17)Results were received more quickly than physical examination which is the best advantage of online assessment.

18)Learners would prefer using online assessment rather than physical examination on the campus.

19)I believe that technologies are difficult to implement for online assessment.

20) There is a lack of direction being provided by the ministry of education for online assessments in educational organizations.

21)Online assessment is part of a strategy to increase success rate by the universities.

22) The availability or structure of the technology (e.g. Wi-Fi, network, PCs) impacts on my e-assessment?

23) My digital literacy is good to cope with online assessment environments.

24)More innovative use of e-assessment across all qualifications is critical.

25)It is better to provide more use of assessment opportunities outside the classroom.

26)It is better to provide more online mock exams before conducting the final e-assessment.

27)I have managed to achieve better grades in online assessment than physical assessment.

28)I have converted my grades to PASS, as I was not satisfied with my performance of online assessment.

29)I would like all future exams to be conducted online.

TABLE I: DATA FINDINGS AND ANALYSIS

\begin{tabular}{|c|c|c|c|c|c|}
\hline $\begin{array}{l}\text { Q. } \\
\text { No. }\end{array}$ & $\begin{array}{c}\text { Strongly } \\
\text { Agree }\end{array}$ & Agree & Neutral & Disagree & $\begin{array}{l}\text { Strongly } \\
\text { Disagree }\end{array}$ \\
\hline 1 & $20.5 \%$ & $52.6 \%$ & $16.7 \%$ & $3.8 \%$ & $6.4 \%$ \\
\hline 2 & $23.1 \%$ & $42.9 \%$ & $16.7 \%$ & $11.5 \%$ & $5.8 \%$ \\
\hline 3 & $20.5 \%$ & $50.6 \%$ & $16 \%$ & $9.6 \%$ & $3.2 \%$ \\
\hline 4 & $21.8 \%$ & $42.9 \%$ & $29.5 \%$ & $5.1 \%$ & $0.6 \%$ \\
\hline 5 & $17.6 \%$ & $26.3 \%$ & $30.1 \%$ & $14.7 \%$ & $10.9 \%$ \\
\hline 6 & $10.9 \%$ & $31.4 \%$ & $28.2 \%$ & $21.2 \%$ & $8.3 \%$ \\
\hline 7 & $18.6 \%$ & $47.4 \%$ & $21.8 \%$ & $10.3 \%$ & $1.9 \%$ \\
\hline 8 & $28.8 \%$ & $48.1 \%$ & $19.9 \%$ & $1.9 \%$ & $1.3 \%$ \\
\hline 9 & $17.9 \%$ & $38.5 \%$ & $21.2 \%$ & $14.1 \%$ & $8.3 \%$ \\
\hline 10 & $25 \%$ & $42.3 \%$ & $20.5 \%$ & $12.2 \%$ & $0 \%$ \\
\hline 11 & $26.3 \%$ & $34.6 \%$ & $20.5 \%$ & $16 \%$ & $2.6 \%$ \\
\hline 12 & $15.4 \%$ & $46.8 \%$ & $26.3 \%$ & $7.1 \%$ & $4.5 \%$ \\
\hline 13 & $17.9 \%$ & $33.3 \%$ & $21.2 \%$ & $18.6 \%$ & $9 \%$ \\
\hline 14 & $17.9 \%$ & $30.8 \%$ & $32.7 \%$ & $12.8 \%$ & $5.8 \%$ \\
\hline 15 & $24.4 \%$ & $44.2 \%$ & $25.6 \%$ & $3.2 \%$ & $2.6 \%$ \\
\hline 16 & $17.9 \%$ & $44.9 \%$ & $22.4 \%$ & $9 \%$ & $5.8 \%$ \\
\hline 17 & $28.8 \%$ & $42.3 \%$ & $21.8 \%$ & $6.4 \%$ & $0.6 \%$ \\
\hline 18 & $15.4 \%$ & $37.8 \%$ & $28.8 \%$ & $12.8 \%$ & $5.1 \%$ \\
\hline 19 & $10.3 \%$ & $31.4 \%$ & $29.5 \%$ & $27.6 \%$ & $1.3 \%$ \\
\hline 20 & $12.8 \%$ & $37.8 \%$ & $37.2 \%$ & $11.5 \%$ & $0.6 \%$ \\
\hline 21 & $14.1 \%$ & $46.8 \%$ & $28.2 \%$ & $9 \%$ & $1.9 \%$ \\
\hline
\end{tabular}




\begin{tabular}{|c|c|c|c|c|c|}
\hline 22 & $30.1 \%$ & $46.2 \%$ & $19.2 \%$ & $3.8 \%$ & $0.6 \%$ \\
\hline 23 & $16.7 \%$ & $51.9 \%$ & $30.1 \%$ & $1.3 \%$ & $0 \%$ \\
\hline 24 & $14.4 \%$ & $45.5 \%$ & $37.2 \%$ & $3.2 \%$ & $0 \%$ \\
\hline 25 & $19.2 \%$ & $48.1 \%$ & $27.6 \%$ & $4.5 \%$ & $0.6 \%$ \\
\hline 26 & $28.2 \%$ & $45.5 \%$ & $22.4 \%$ & $3.2 \%$ & $0.6 \%$ \\
\hline 27 & $19.2 \%$ & $41.7 \%$ & $26.9 \%$ & $9.6 \%$ & $2.6 \%$ \\
\hline 28 & $17.3 \%$ & $34.6 \%$ & $17.3 \%$ & $19.9 \%$ & $10.9 \%$ \\
\hline 29 & $18.6 \%$ & $30.1 \%$ & $30.8 \%$ & $9 \%$ & $11.5 \%$ \\
\hline
\end{tabular}

that online assessment contains different techniques during the course of assessments. Such as a sequential approach of the questions where students are not allowed to visit their previous questions once answered. Such techniques make time management difficult for student conducting online assessments.

The survey of this research also found that major of students $46.8 \%$ believe that online assessment is consistent with teaching styles. Further, most participants agree that online assessments are more efficient and effective than physical exams on campus. However, the majority of survey participants were neutral that online assessments are more systematic than physical examinations on campus.

User interface and the usability of online assessment is critical for the success of online assessments. The survey of this research found that majority of participants are happy with the user interface/tool used for online assessments by their university. Therefore, most survey participants agree that online assessments offer more opportunities than paper alone based assessments. A vast major of the students were found happy due to the efficiency of online assessments as they believe that results were received more quickly than physical examination which is the best advantage of online assessment. It is, therefore, most participants agree that learners would prefer using online assessments rather than physical examinations on the campus. Further, most participants agreed, were neutral or disagreed towards technologies being difficult to implement for online assessment.

The findings of the survey revealed that $37.8 \%$ agreed and $37.2 \%$ are neutral towards the statement that there is a lack of direction being provided by the ministry of education for online assessments in educational organizations and major of the students agree that online assessment is part of a strategy to increase success rate by the universities.

The majority of survey participants $46.2 \%$ agreed while other $30.1 \%$ strongly agree that the availability or structure of technology impacts on their e-assessment. Other 51.9\% agree that their digital literacy is good to cope with online assessment environments. However, the majority of survey participants believe that more innovative use of e-assessment across all qualifications is critical and they agree with the statement that it is better to provide more use of assessment opportunities outside the classroom to enhance their skills. To enhance such skills majority of participates of this survey were found agree that it is better to provide more online mock exams before conducting the final e-assessment.

The survey of this research also revealed that $41.7 \%$ agree and $19.2 \%$ strongly agree that they have managed to achieve better grades in online assessment than physical assessment. However, those who could not perform well as a result of online assessments they have converted their grades to PASS, as they were not satisfied with their performance of online assessment for the purpose to maintain their GPA and CGPA. About half of the survey participants believe that they would like all future exams to be conducted online.

\section{DATA FindingS FROM SEMI StRUCTURED INTERVIEWS}

In overall, 30 students were interviewed about their views 
on online education and assessment. Each student commented on their opinion of online education. Whilst some were eager to return to the university campus for their assessments and lectures, others chose not to give any comment.

One student commented that they had a preference to study in the university, as teaching within the university is more understandable than in online. This shows that students find it easier to learn in a classroom as they have a better connection to the teacher who can answer any questions more effectively. Another student commented that it is unfair for students to take online assessments as the tools used to conduct the assessments rely on Wi-Fi. Therefore, students with a bad connection may not be able to understand the online commands or information given to the teacher. If students were at the university this problem would not occur and the information given would be understandable to all the students, making it fair.

Other students commented that online learning and assessment allows them to have more flexible time. One student commented that as an employer, online education allows us to save lots of time and effort. This allows them to manage their schedule more effectively and efficiently. Another student quoted that since classes are online, they are not tardy and can get to the online class easily as they will not have to travel far.

Another student quoted that online assessments are unfair as many students can cheat easily. The student quoted that others achieved full marks without studying as they were able to use their notes while conducting the assessment. This could demotivate other students who are not cheating and reward those who are. This shows that online assessments can be unfair and inaccurate of the student's ability and knowledge in the subject as they are cheating.

\section{Performance Analysis Based on the ReAl Data OF STUDENT'S TRANSCRIPTS}

The authors of this research analyzed 61 students' transcripts from two different universities. The analyses were conducted from different majors such as Engineering, Information Technology, and Information Systems. For the purpose to make sure that appropriate discussion is formed, and data is fully analyzed, the author's studies student's transcripts from the year 2016, 2017, 2018 and 2019. The data of these transcripts are kept confidential.

The effect of online assessments implemented on the second semester of 2019-2020 due to COVID-19 on the GPA and CGPA of students were analyzed. As per the policy of Ministry of Education UAE, universities have offered students with the choice to convert their grades after online assessment to "Pass (P)" if they are not satisfied with the achieved grades such as D or above and "Not Pass (NP)" to replace "Fail (F)". The analysis of the student's transcripts revealed that majority of students whose grade in the course looks below the CGPA, have selected the option P/NP. All students with F naturally would prefer to have it as "NP", with no impact on their CGPAs and their status, shown in Table II below.
TABLE II: PERFORMANCE ANALYSIS OF STUDENT'S TRANSCRIPTS

\begin{tabular}{|l|c|c|c|}
\hline $\begin{array}{l}\text { Year of } \\
\text { Exams }\end{array}$ & $\begin{array}{c}\text { Total } \\
\text { number of } \\
\text { transcripts } \\
\text { analyzed }\end{array}$ & $\begin{array}{c}\text { Number of students } \\
\text { who } \\
\text { select part of their } \\
\text { grades to be } \\
\text { replaced with P/NP }\end{array}$ & $\begin{array}{c}\text { Number of } \\
\text { students who } \\
\text { select all their } \\
\text { grades to be } \\
\text { replaced with } \\
\text { P/NP }\end{array}$ \\
\hline $\mathbf{2 0 1 6}$ & 16 & 3 & 3 \\
\hline $\mathbf{2 0 1 7}$ & 7 & 5 & 0 \\
\hline $\mathbf{2 0 1 8}$ & 20 & 9 & 2 \\
\hline $\mathbf{2 0 1 9}$ & 18 & 0 & 0 \\
\hline
\end{tabular}

Table II above is the evidence that 5 students selected the $\mathrm{P} / \mathrm{NP}$ for all of their grades for the purpose to make sure that their CGPAs would not have been affected and the reason is simple. From the student's view, this is considered as a wise decision. Further, 17 students partially selected their grades to be converted to P/NP which would have lowered their CGPAs. Obviously, students should have selected the option of P/NP for any grade that is lower than their CGPAs. However, not all of the students selected this option as the authors of this research observed from their transcripts and it was found that student did not replace their grades for courses that below CGPA with P/NP. From the findings and analysis it was concluded that this could be due to the reason that they do not understand the P/NP option or they may prefer to have grades in their transcripts instead of P/NP. This could be the long-term strategy of these students.

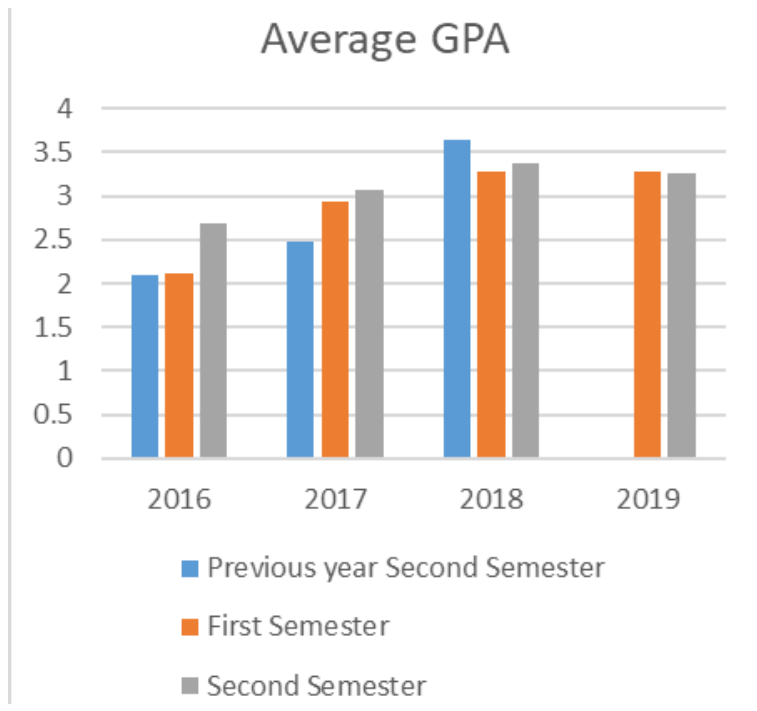

Fig. 2. GPA on the last three semesters for students from years 2016-2019.

Further analysis of the transcripts by the authors of this research found that usually students have the highest GPA in the early semester of their studies and afterward their GPAs start to decline as they begin to take major courses. The below Fig. 2, 3, 4, 5, 6 and 7 shows the analysis of these students from year 2016 to 2019 for their Grade Point Average (GPA) and Cumulative Grade Point Average (CGPA). Therefor, 2016 batch benefit from the online assessment and their GPA increased dramatically in comparison to 2017, 2018, and 2019 batches as shown in Fig. 2 and 4. For students from years 2017- 2019, their GAPs either increased or remained still which is also an achievement for them (see Fig. 2b, 2c, and 2d). Students from years 2017 and 2018 maintain the same level of GPA as some students have selected the option of P/NP for courses that would lower their GPAs. Student form year 2019 are first 
year and obviously the type of courses they are doing from the first level and manage to achieve high grades with the online assessment and did not uses the option of P/NP. Fig. 3 shows that all the different batches were able to preserve their CGPA over the second semester of year 2019-2020.

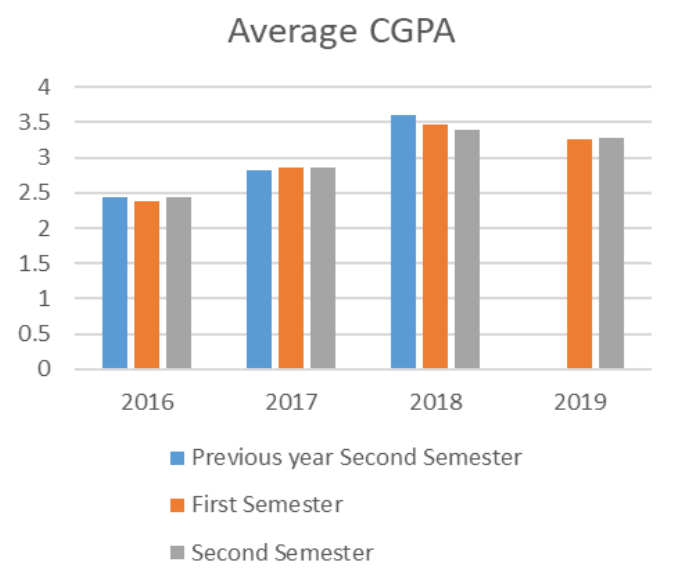

Fig. 3. CGPA for students from years 2016-2019.

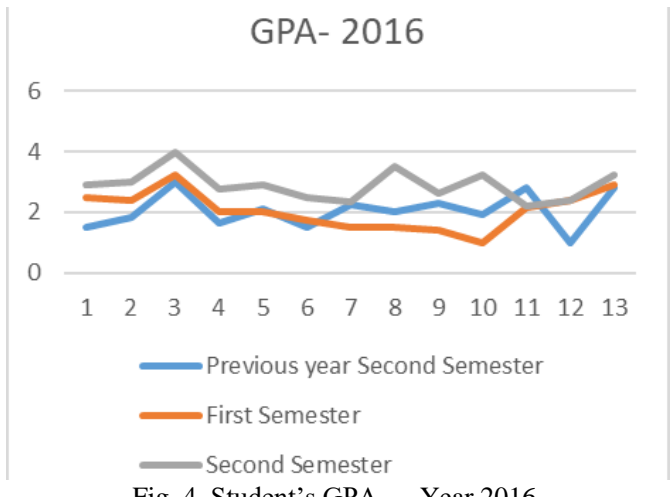

Fig. 4. Student's GPA - Year 2016.

\section{GPA-2017}

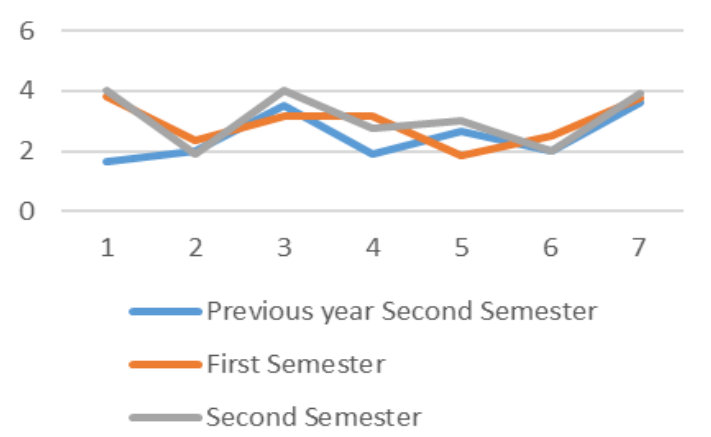

Fig. 5. Student's GPA - Year 2017.

GPA- 2018

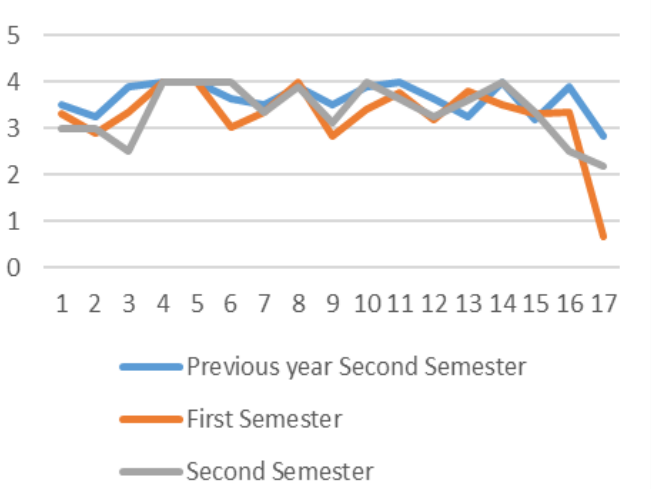

Fig. 6. Student's GPA - Year 2018.

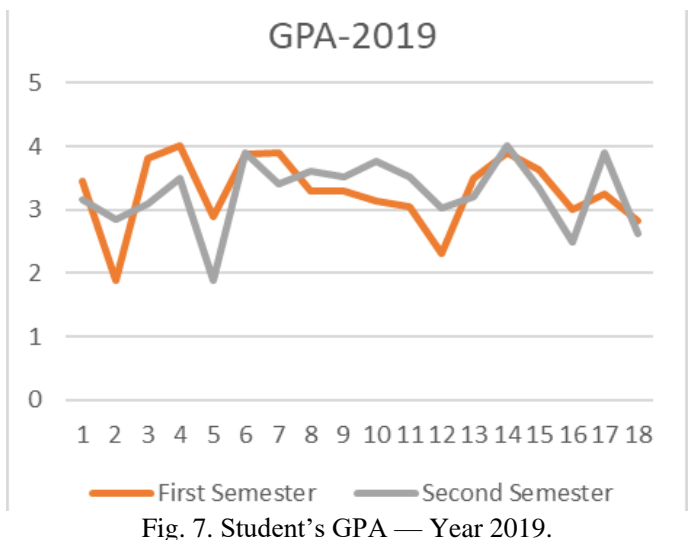

\section{RECOMMENDATIONS}

The research in this paper recommends the following for the purpose of appropriate form of assessment that must be designed for students participating in online assessment. The recommendations of this research are beneficial not for the universities in the region of UAE only but could be applied in all universities regardless of their location.

Ministries of Education and other educational institutions must review their policies in order to implement an online assessment system to provide students with a robust and reliable area to perform their assessments.

When designing e-assessment, developers must consider the reliability of the program and its safety along with ensuring its fairness among all students.

Each university should establish student's enquiry system to help the students who encounter problems during the online courses as well as online assessment. Some students might not be familiar with the technologies and tools they will be using during the online classes. Therefore, they must be provided with adequate training to be aware of the tools used during online classes.

Advanced remote invigilation mechanisms should be used to create the same exam experience in physical classes on campus. The "Virtual Invigilator" model should be adopted to achieve effective proctoring and students will be continuously monitored while doing their assessments.

Lecturers should move away from traditional types of questions such as multiple choice and essay questions and use other types of questions such as open-book style questions or multimedia questions. Online assessment should open the door for creating a diverse range of assessment.

Cybersecurity should be considered as a threat to the online assessment process. Therefore, security services (e.g. confidentiality, Integrity, and Authenticity) must exist during the course of online assessment.

The use of third-party software that aims to prevent cheating during online assessments should also be taken into consideration. For example, a 'Lockdown Browser', which prevents the use of search engines and the internet during assessment.

Senior management, administration and operational management must fulfil their responsibilities in developing and supporting e-assessment strategies, policies, and accountability for the e-assessment process.

An appropriate form of environment suitable for 
e-assessment must be provided as per the policies of each university.

Only technical support should be provided to students during the course of e-assessment and no other help should be there by which students can understand or answer any e-assessment question or part.

All incidents must be recorded. This may include down time of the server, issue of connectivity, Wi-Fi connections or any other event that could create a barrier during the course of online assessments.

There is a need for international standards and best practices that should be adopted while preparing e-assessment for students at all levels.

\section{CONFLICT OF INTEREST}

The authors declare no conflict of interest.

\section{AUTHOR CONTRIBUTIONS}

Dr. Liaqat Ali is the primary researcher of this work. Section VII 'Performance analysis based on the real data student's transcripts' is analyzed by the second author, Dr. Nidal Al Dmour.

\section{REFERENCES}

[1] WHO. (2020). Coronavirus disease (COVID-19) pandemic. World Health Organization. [Online]. Available: https://www.who.int/emergencies/diseases/novel-coronavirus-2019

[2] UNESCO. (2020). Education: From disruption to recovery. COVID-19 Impact on Education. [Online]. Available: https://en.unesco.org/covid19/educationresponse

[3] Talent-LMS. (2020). The benefits and drawbacks of online learning. [Online]. Available: https://www.talentlms.com/elearning/benefits-and-drawbacks-of-onlin e-learning

[4] S. Armstrong, "What are the advantages and disadvantages of online learning?" E-Learning Industry, 2013.

[5] A. E. G. Roldán et al., "Pedagogical approaches for e-assessment with authentication and authorship verification in higher education," British Journal of Educational Technology, vol. 50, no. 6, 2019, pp. 3264-3282, doi:10.1111/bjet. 12733 .

[6] (2020). Advantages and disadvantages of online examination system. [Online].

Available: https://www.onlineexambuilder.com/knowledge-center/exam-knowle dge-center/advantages-and-disadvantages-of-online-examination-syst $\mathrm{em} / \mathrm{item} 10240$

[7] P. Hoarder, "What are the advantages and disadvantages of online assessment help?" 2020.

[8] Paatham. (2019). Advantages \& Disadvantages of Online Examination System. [Online]. Available: https://medium.com/@tanishadutta647/advantages-disadvantages-of-o nline-examination-system-edf7b37bdc11

[9] P. I. Wuisan and B. Wibawa, "Using electronic assessment system in higher education: Challenges and solutions for lectures, students and institutions," International Journal of Recent Technology and Engineering (IJRTE), ISSN: 2277-3878, vol. 8, issue 2S9, September 2019.

[10] N. A. Buzzetto-More and A. J. Alade, "Best practices in e-assessment," Journal of Information Technology Education, vol. 5, 2006.

[11] N. N. Omar and Y. J. Phung, "E-assessment: Developing technology application prototype for easy evaluation of students' assignments," International Journal of Information and Education Technology, vol. 9, no. 4, April 2019.

[12] O. Alexandra, W. Denise, and H. Wayne, S"tudents' views on trust-based e-assessment system for online and blended environments," presented at the Online, Open and Flexible Higher Education Conference, 2017, Open University, Milton Keynes.

[13] M. Appiah and F. V. Tonder, "E-assessment in higher education: A review," International Journal of Business Management and Economic Research (IJBMER), vol. 9, no. 6, 2018, pp. 1454-1460, ISSN: 22296247.
[14] S. Timmis, P. Broadfoot, R. Sutherland, and A. Oldfield, "Rethinking assessment in a digital age: Opportunities, challenges and risks," British Educational Research Journal, vol. 42, no. 3, pp. 454-476, 2016.

[15] T. R. Fontanillas, M. R. Carbonell, and M. G. Catasús, "E-assessment process: Giving a voice to online learners," Int J Educ Technol High Educ, vol. 13, no. 20, 2016.

[16] N. Alruwais, G. Wills, and M. Wald, "Identifying factors that affect the acceptance and use of e-assessment by academics in Saudi Universities," IJAEDU- International e-Journal of Advances in Education, vol. 2, issue 4, April 2016.

[17] N. Alruwais, G. Wills, and M. Wald, "Validating factors that impact the acceptance and use of e-assessment among academics in Saudi Universities," International Journal of Information and Education Technology, vol. 7, no. 10, October 2017.

[18] M. E. Rodríguez et al., "Adaptive e-assessment system: A general approach," International Journal of Emerging Technologies in e-Learning (iJET), vol. 11, issue 7, 2016.

[19] A. Astalini et al., "Effectiveness of using e-module and e-assessment," International Journal of Interactive Mobile Technologies (iJIM), volume 13, 2019.

[20] B. Bahati et al., "Measuring learner satisfaction with formative e-assessment strategies," International Journal of Emerging Technologies in Learning (iJET), eISSN: 1863-0383, vol. 14, no. 7, 2019.

[21] K. P. Hewagamage and G. N. Wikramanayake, "Designing formative e-assessments to prepare students for the summative assessment in massive online courses," International Journal of Information and Education Technology, vol. 1, no. 4, October 2011.

[22] D. Al-Shaikhli and S. Courtenage, "A literature review of personalisation, search, and navigation methods in open e-learning," International Journal of Information and Education Technology, vol. 8, no. 1, January 2018.

[23] I. Sikurajapathi, K. Henderson, and R. Gwynllyw, "Using e-assessment to address mathematical misconceptions in engineering students," International Journal of Information and Education Technology, vol. 10, no. 5, May 2020, doi: 10.18178/ijiet.2020.10.5.1389.

[24] S. Bennett and T. Barker, "The use of electronic voting and peer assessment to encourage the development of higher order thinking skills in learners," International Journal of e-Assessment, vol. 2, no. 1, 2012.

[25] H. Alsadoon, "Students' perceptions of e-assessment at Saudi Electronic University," TOJET: The Turkish Online Journal of Educational Technology, January 2017, vol. 16 issue 1.

[26] Z. G. Baleni, "Online formative assessment in higher education: Its pros and cons," The Electronic Journal of e-Learning, vol. 13, issue 4, 2015, pp. 228-236.

[27] P. Padayachee et al., "Online assessment in Moodle, a framework for supporting our students," South African Journal of Higher Education, vol. 32, no. 5, 2018, pp. 211-235, eISSN 1753-5913.

[28] K. Shraim, "Online examination practices in higher education institutions: Learner's perspective," Turkish Online Journal of Distance Education-TOJDE, October 2019, ISSN 1302-6488, vol. 20 no. 4 , article 12.

[29] N. Alruwais, G. Wills, and M. Wald, "Advantages and challenges of using e-assessment," International Journal of Information and Education Technology, vol. 8, no. 1, January 2018.

[30] R. D. Villiers, J. Scott-Kennel, and R. Larke, "Principles of effective e-assessment: A proposed framework," Journal of International Business Education, vol. 11, pp. 65-92. 2016.

[31] W. Muhamada and W. Wikusna, "Software architecture of e-assessment on higher education," International Journalof Applied Information Technology, vol. 01, no. 02, 2017.

[32] M. Cubric and M. Tosic. Towards automatic generation of e-assessment using semantic web technologies. [Online]. Available: https://uhra.herts.ac.uk/bitstream/handle/2299/7785/904296.pdf?sequ ence $=1$

Copyright $\odot 2021$ by the authors. This is an open access article distributed under the Creative Commons Attribution License which permits unrestricted use, distribution, and reproduction in any medium, provided the original work is properly cited (CC BY 4.0). 


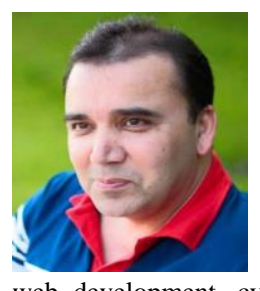

Liaqat Ali completed his $\mathrm{PhD}$, information systems, in 2008 from University of East London UK. He was associated with many international universities since 2005 and has supervised more than 125 postgraduate research dissertations. He is currently working in University of Science and Technology of Fujairah UAE. Dr Ali's principal research area for several years has been in the field of IS, e-accessibility and web development, cyber-crimes, and business information systems. His research activities cover e-accessibility, web development, cyber-crimes and computer security, business information systems and managemen information systems. For further information on Dr Ali's profile, please visit https://liaqat22.wixsite.com/drali

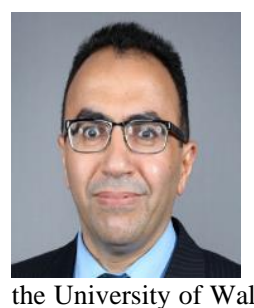

Nidal Al-Dmour is an associate professor at Ajman University college of Information Technology. Before joining Ajman University in 2013, Dr Al-Dmour was serving as an associate professor at College of Engineering Mutah University in Jordan In 1998, he was awarded a BSc in electrical engineering/communications from Mutah University.

He commenced his postgraduate studies in 1999 at the University of Wales Bangor, United Kingdom. He achieved the MSc in computer networks with distinction in 2000. He has completed his $\mathrm{PhD}$ in 2005 in high performance computing and computer networks. His research interests include computer networks, modelling and simulation, cloud computing, and e-government. 